\title{
Smooth handling: The lack of safety-related consumer information in car advertisements
}

\author{
Nick Wilson, Anthony Maher, George Thomson, Michael Keall
}

Injury Prevention 2007;13:304-306. doi: 10.1136/ip.2007.016402

See end of article for authors' affiliations

Correspondence to:

Dr Nick Wilson, Department of Public Health, University of Otago, Wellington, PO Box 7343, Wellington

South, New Zealand; nick. wilson@otago.ac.nz

Accepted 9 August 2007
Objective: To examine the content and trends of safety-related consumer information in magazine vehicle advertisements, as a case study within the worldwide marketing of vehicles.

Methods: Content analysis of popular current affairs magazines in New Zealand for the 5-year period 20012005 was undertaken ( $n=514$ advertisements), supplemented with vehicle data from official websites. Results: Safety information in advertisements for light passenger vehicles was relatively uncommon with only $27 \%$ mentioning one or more of nine key safety features examined (average: 1.7 out of nine features in this $27 \%$ ). Also included were potentially hazardous features of: speed imagery (in 29\% of advertisements), power references $(14 \%)$, and acceleration data $(4 \%)$. The speed and power aspects became relatively more common over the 5 -year period ( $p<0.05$ for trend).

Conclusions: To enhance informed consumer choice and improve injury prevention, governments should consider regulating the content of vehicle advertisements and vehicle marketing - as already occurs with many other consumer products.
$\mathrm{R}$ oad traffic injury is a major and preventable global problem as detailed in a recent report by the World Health Organization. ${ }^{1}$ The marketing of vehicles is a worldwide phenomenon and such marketing has been studied previously, due to concerns that it may adversely influence safety-related behaviours. ${ }^{2-6}$ Given the major expenditure that manufacturers and retailers invest in vehicle marketing ${ }^{5}$ it is likely to have some impact on consumer behaviour (as reviewed elsewhere ${ }^{5}$ ). More generally, there is evidence that marketing works, ${ }^{7}$ including advertising in magazines. ${ }^{8}$

Yet research on safety and vehicle marketing is still limited, in that few studies have been published, there is a lack of time trend analyses and there are no publications relating to printed advertisements. We used data from New Zealand to examine vehicle marketing as this country provided a convenient example of a developed country (e.g. a member of the OECD). In particular, we undertook a content analysis of light passenger vehicle advertising in magazines and examined safety-related consumer information.

\section{METHODS}

\section{Magazine selection and search strategy}

We selected magazines as these have more frequent and consistent coverage of vehicle advertisements than do newspapers and provide more informational content than television advertisements. The two highest circulation monthly current affairs magazines specific to New Zealand were selected (i.e. Metro and North \& South). All the issues for the 5-year period from 2001 to 2005 were hand-searched on a page-by-page basis and if the vehicle advertisement took up more than a quarter of the page, then it was included in the study and photocopied. Only advertisements that dealt with a specific model of car, sports utility vehicle (SUV) or similar light vehicle (primarily for passengers, with fewer than eight seats), were considered.

\section{Safety data for the content analysis}

Data were collected from the advertisements on vehicle-specific safety aspects. The priority safety features considered were based largely on a US 'Consumer Reports' list of safety checks to use before buying a vehicle. ${ }^{9}$ This grouping (CR9) covered: air bags, antilock brake systems (ABS), electronic stability control, roll-over protection, pre-crash systems (i.e. brake assist, emergency steering assist or headrest adjustment), head restraints, seat-belt pre-tensioners, child safety issues (including ISO-FIX seating), and safety rating (crash test) scores or levels. A further 'additional safety' category was created for the following nine features: electronic break-force distribution, emergency braking systems, downhill braking, hill descent control, traction or dynamic control, low centre of gravity, side impact protection, body reinforcements, and crumple zones.

Data were also collected from the advertisements on features that could be considered to be potentially hazardous (from an injury perspective). These included speed imagery (e.g. blurring of the image background, and skid marks); the use of specific quotes promoting excessive speed or power and unsafe driving (e.g. mention of cornering at excessive speed, and driving like a rally or Formula l vehicle); and the mention of specific acceleration statistics (e.g. the time it takes to reach $100 \mathrm{~km} /$ h). To establish the context of safety trends, additional data were obtained on crash test ratings for the specific vehicles shown in the magazine advertisements from both an official government website (www.ltsa.govt.nz/vehicles/ancap/ index.html) and a European website (www.euroncap.com).

SUVs have been reported to have an increased roll-over risk ${ }^{10}$ and to increase the likelihood of pedestrian fatality relative to car collisions with pedestrians. ${ }^{11}{ }^{12}$ However, we did not separately analyse patterns associated with the advertising of SUVs from a safety perspective in this study, given that SUVs in Australasia appear to be driven relatively safely by low-risk driver groups and increases in road trauma do not seem to have occurred despite the increased popularity of SUVs. ${ }^{13}$

\section{Data collation and analysis}

Data were analysed using EpiInfo (CDC, Atlanta). To best approximate the advertisement impact on consumers exposed to the magazines, the unit of analysis was a particular advertisement in a particular issue. This meant a larger contribution in the results from advertisements that were repeated in subsequent issues or appeared in both magazines. 


\section{Validation study}

As only a single person (A.M.) classified the advertisement content, a validation study using another person was conducted. It included a 5\% random sample of all advertisements $(n=26)$, and a $15 \%$ random sample of those advertisements classified as portraying speed imagery $(n=21)$, given that the latter was the most subjective aspect to classify. The inter-rater reliability ranged from $89 \%$ for speed imagery upwards (i.e. 'additional safety' data (92\%), SUV (94\%), 4WD/AWD (94\%), CR9 (96\%), and acceleration (100\%)).

\section{RESULTS}

\section{Overall advertising patterns}

A total of 514 relevant advertisements were identified for the 5year period ( $n=279$ for Metro, $n=235$ for North \& South). This was made up by a total of 149 different vehicles (determined by vehicle model and engine specifications). The average size for the advertisements was 1.3 pages.

\section{Specific safety aspects}

Over the 5 -year period only $27 \%$ of advertisements mentioned at least one of nine key CR9 safety features (see Table 1). There was a statistically significant increase over time of such features being mentioned $(p=0.02$, chi squared for linear trend, Mantel Extension). The frequency by which these key features were mentioned (out of all advertisements) were electronic stability control (17.3\%), air bags $(13.8 \%)$, antilock brake systems $(10.7 \%)$, safety ratings $(5.6 \%)$, pre-crash systems $(4.1 \%)$, head restraints $(2.1 \%)$, roll-over protection $(0.4 \%)$, seat-belt pre-tensioners $(0.4 \%)$, and child safety issues $(0.2 \%)$. The mean crash rating data (ANCAP ratings from NZ Government and European websites) for the advertised vehicles were consistently high (at $4+$ out of 5 for both scales) for each year and did not change significantly over time (Table 1).

Only $14 \%$ of advertisements mentioned one or more of the additional nine 'additional safety' features, although there was a significant increase over the 5 years (Table 1 ). In the advertisements with any safety information, the overall average number of CR9 and 'additional safety' features per advertisement was 1.7 and 1.4 respectively (out of a possible nine in each category).

Overall, 39\% advertisements included at least one potentially hazardous feature (Table 1) and $4 \%$ of advertisements mentioned a specific acceleration statistic (e.g. $0-100 \mathrm{~km} / \mathrm{h}$ in $6.3 \mathrm{~s}), 29 \%$ included speed imagery, and $14 \%$ made specific reference to increased power or acceleration. The latter two categories both showed increasing proportions over the 5-year period at statistically significant levels.

\section{Vehicle company websites}

Although $89 \%$ of advertisements had websites listed, there were only a total of 29 separate vehicle manufactures and websites involved. Of these websites, all but one (97\%) provided some data about the various safety features.

\section{DISCUSSION \\ Interpretation}

This analysis indicated that safety information in magazine advertisements for light passenger vehicles is relatively uncommon in this particular developed country. For example, only $27 \%$ mentioned one or more of nine key safety features (CR9), these averaging only 1.7 such features per advertisement. The content of some advertisements also included the hazardous features of speed imagery (in 29\%) and power references (14\%) and these became relatively more common over the 5-year period.

The New Zealand code for motor vehicle advertising is a voluntary one and it states that 'Advertisements should not glorify excessive speed and/or unsafe driving practices' ${ }^{14}$ It would seem that the use of speed imagery and/or the use of power references found in this study are not compatible with the intent of this advertising code. Specific acceleration statistics (i.e. $0-100 \mathrm{~km} / \mathrm{h}$ in $6.3 \mathrm{~s}$ ) would also be a breach of codes used in other countries, e.g. Australia. ${ }^{15}$

While safety information became more common in the advertisements, the actual safety of the vehicles advertised (based on the website data on crash test ratings), did not significantly improve. This suggests that annual increments in safety design for the new vehicle models advertised are small.

\section{Limitations}

This study was limited to a small sample of printed media (albeit the two major monthly current affairs magazines with a wide readership) containing advertisements for light passenger vehicles. Also, the validation study suggested that the classification of speed imagery was less accurately rated than the other information obtained from the advertisements (i.e. with an inter-rater reliability of $89 \%$ compared to the $92-100 \%$ range for the other variables). Therefore the speed imagery results need to be considered as only generally indicative of the likely true pattern.

It is of note that there has been criticism of the five-star crash test rating scales used for vehicles. That is, with the majority of

Table 1 Mean crash test ratings of advertised vehicles and coverage of positive safety features and hazardous aspects in the advertisements

\begin{tabular}{|c|c|c|c|c|c|c|c|c|c|}
\hline \multirow[b]{3}{*}{$\begin{array}{l}\text { Year/ } \\
\text { Magazine }\end{array}$} & \multicolumn{4}{|c|}{ Crash test rating* } & \multicolumn{2}{|l|}{ Safety features } & \multicolumn{3}{|c|}{ Potentially hazardous features } \\
\hline & \multicolumn{2}{|c|}{ New Zealand } & \multicolumn{2}{|c|}{ Euro NCAP } & \multirow{2}{*}{$\begin{array}{l}\text { Any of the } 9 \text { key } \\
\text { features (CR9), ,* } \\
n(\%)\end{array}$} & \multirow{2}{*}{$\begin{array}{l}\text { Any of the } \\
\text { additional safety } \\
\text { features, }^{* *} n(\%)\end{array}$} & \multirow[b]{2}{*}{$\begin{array}{l}\text { Speed imagery } \\
\text { shown, }{ }^{* *} n(\%)\end{array}$} & \multirow{2}{*}{$\begin{array}{l}\text { Mentions } \\
\text { acceleration data, } \\
n(\%)\end{array}$} & \multirow[b]{2}{*}{$\begin{array}{l}\text { Power reference, } \\
n(\%)\end{array}$} \\
\hline & $\begin{array}{l}\text { Mean } \\
\text { rating }\end{array}$ & $n$ & $\begin{array}{l}\text { Mean } \\
\text { rating }\end{array}$ & $n$ & & & & & \\
\hline 2001 & 4.2 & 40 & 4.0 & 32 & $10(14.7)$ & $3(4.4)$ & $18(26.5)$ & $5(7.4)$ & $4(5.9)$ \\
\hline 2002 & 4.4 & 40 & 4.3 & 39 & 11 (18.0) & 11 (18.0) & $10(16.4)$ & 2 (3.3) & $10(16.4)$ \\
\hline 2003 & 4.3 & 60 & 4.2 & 62 & 35 (33.3) & 24 (22.9) & 32 (30.5) & 7 (6.7) & $16(15.2)$ \\
\hline 2004 & 4.2 & 88 & 4.2 & 83 & $50(30.7)$ & 24 (14.7) & 51 (31.3) & $5(3.1)$ & 20 (12.3) \\
\hline 2005 & 4.4 & 53 & 4.3 & 53 & 33 (28.2) & $12(10.3)$ & 42 (35.9) & $2(1.7)$ & $24(20.5)$ \\
\hline$p$-value $e^{\star * *}$ & & & & & 0.020 & 0.833 & 0.031 & 0.058 & 0.043 \\
\hline Metro & 4.3 & 148 & 4.3 & 147 & $73(26.2)$ & 37 (13.3) & $84(30.1)$ & $12(4.3)$ & $39(14.0)$ \\
\hline North \& South & 4.2 & 133 & 4.1 & 122 & $66(28.1)$ & 37 (15.7) & $69(29.4)$ & $9(3.8)$ & 35 (14.9) \\
\hline Total & 4.3 & 281 & 4.2 & 269 & $139(27.0)$ & 74 (14.4) & $153(29.0)$ & $21(4.0)$ & 74 (14.4) \\
\hline
\end{tabular}

*Crash test ratings (score 1-5) sourced using a New Zealand and European website (see Methods).

${ }^{* *}$ See the Methods section for definitions.

*** $p$-value for chi squared for linear trend, Mantel Extension. 


\section{Key points}

- Vehicle marketing is a worldwide phenomenon and previous studies have indicated that vehicle advertising may not support, and may even counter, road safety messages.

- This content analysis of 514 advertisements in New Zealand magazines found that safety information was relatively uncommon. Only $27 \%$ mentioned one or more of nine key safety features.

- Some advertisements also included the potentially hazardous features of: speed imagery, power references and acceleration data.

- To enhance informed consumer choice and improve injury prevention, governments should consider regulating the content of vehicle advertisements and vehicle marketing.

vehicles obtaining four stars it is difiicult for consumers to detect differences and for manufacturers to have incentives to improve safety further. ${ }^{16}$

\section{Possible implications for policy makers}

The findings of this study (when consideried with the other published work to date) raise concerns about the nature of vehicle advertising from a safety perspective. Further research on vehicle advertising in other media is therefore desirable, as are more systematic comparison studies between countries. Nevertheless, as marketing of vehicles involves such large financial investments, ${ }^{5}$ it is likely that the safety-related information and themes in this advertising is of relevance to public health internationally.

To maximise the opportunities to ensure that consumers have adequate information for decision making in welltargeted ways, governments may wish to better regulate the safety aspects of vehicle advertising (and potentially other health-related aspects such as air pollution and the emission of greenhouse gases from vehicle exhausts). There are a number of precedents for requiring consumer information in other product areas. Indeed, many developed countries have detailed regulations that require safety information in all pharmaceutical advertisements, health warnings on all tobacco and alcohol products, nutrition labels on packaged food, and energy efficiency labels on appliances. Given this context there is a public health case to expand regulations around key vehicle safety information (in both symbols and text) and to restrict hazardous content of advertising such as speed imagery. This may also mean that governments receive better value for money from their road safety campaigns, rather than these being countered by the messages used in vehicle marketing. While industry may prefer voluntary agreements to regulation, the former are much less likely to be effective, given the generally unsuccessful experience with voluntary agreements in controlling tobacco industry marketing and the output of pollutants from industries producing greenhouse gases.

\section{CONCLUSIONS}

Most of the advertisements for light passenger vehicle in the magazines reviewed in this study were not informative in terms of safety. Speed imagery and power references can also be considered to be concerns from a safety perspective. To address these issues, governments should consider regulating the content of such advertisements, as is done with various other consumer products such as tobacco, pharmaceuticals and appliances.

\section{Acknowledgements}

The authors thank Emma Williams for assistance with data collection and Sarah Pollock for carrying out the validation study. There was no external funding for this study.

\section{Authors' affiliations}

Nick Wilson, Anthony Maher, George Thomson, Michael Keall, Department of Public Health, University of Otago, Wellington, PO Box 7343, Wellington South, New Zealand

Competing interests: None declared.

\section{REFERENCES}

1 Peden $M$, Scurfield R, Sleet D, et al. World report on road traffic injury prevention. Geneva: World Health Organization, 2004.

2 Ferguson SA, Hardy AP, Williams AF. Content analysis of television advertising for cars and minivans: 1983-1998. Accid Anal Prev 2003;35:825-31.

3 Tamburro RF, Gordon PL, D'Apolito JP, et al. Unsafe and violent behavior in commercials aired during televised major sporting events. Pediatrics 2004; 114:e694-8.

4 Shin PC, Hallett D, Chipman ML, et al. Unsafe driving in North American automobile commercials. J Public Health (Oxf) 2005;27:318-25.

5 Sheehan M, Steinhardt D, Schonfeld C. A content analysis of Australian motor vehicle advertising. Canberra: Australian Transport Safety Bureau, http:// www.atsb.gov.au/publications/2006/pdf/CR228.pdf, 2006.

6 McGwin G, Modjarrad K, Reiland A, et al. Prevalence of transportation safety measures portrayed in primetime US television programs and commercials. Inj Prev 2006;12:400-3.

7 Malhotra NK, Peterson M, Kleiser SB. Marketing research: A state-of-the-art review and directions for the twenty-first century. J Acad Marketing Sci 1999;27:160-83.

8 Dertouzos JN, Garber S. Effectiveness of advertising in different media. J Advertising 2006;35:1 11 1-22.

9 ConsumerReports Organisation. 10 safety checks to make before you buy, Consumers Union of US.http://autos.yahoo.com/consumerreports/article/ safety_checks.html, 2006.

10 Kweon YJ, Kockelman KM. Overall injury risk to different drivers: combining exposure, frequency, and severity models. Accid Anal Prev 2003;35:441-50.

11 Lefler DE, Gabler HC. The fatality and injury risk of light truck impacts with pedestrians in the United States. Accid Anal Prev 2004;36:295-304.

12 Simms C, Wood D. Pedestrian risk from cars and sport utility vehicles - a comparative analytical study. Proceedings of the Institution of Mechanical Engineers, Part D. J Automobile Eng 2006;220:1085-100.

13 Keall M, Newstead S, Watson L. Four-wheel drive vehicle crash involvement patterns. Melbourne: Monash University Accident Research Centre, 2006.

14 Advertising Standards Authority Inc. Code for advertising vehicles, 2005 : Advertising Standards Authority Inc. http://www.asa.co.nz/codes/codes.htm, 2005.

15 Federal Chamber of Automotive Industries. Voluntary code of practice for motor vehicle advertising 2004. Canberra: Federal Chamber of Automotive Industries, http://www.fcai.com.au/files/Code_-_Explanatory_Notes_as_at_24.05.pdf, 2004.

16 Anonymous. Crashworthy motor vehicles [Editorial]. New York Times 3 February 2007: Section A, p. 14. 